\title{
Research on the State Input of China's Higher Education in the Transitional Period: Status Quo, Problems and Countermeasures
}

\author{
Ping Zhao ${ }^{1}$, Yan Luo², Shaogang Liao \\ ${ }^{1}$ Modern Economics \& Management College, Jiangxi University of Finance and Economics, Nanchang, China \\ ${ }^{2}$ School of Public Finance and Public Administration, Jiangxi University of Finance and Economics, Nanchang, China
}

Email address:

liaoshaogang@163.com (Shaogang Liao)

\section{To cite this article:}

Ping Zhao, Yan Luo, Shaogang Liao. Research on the State Input of China's Higher Education in the Transitional Period: Status Quo, Problems and Countermeasures. Social Sciences. Vol. 6, No. 5, 2017, pp. 127-132. doi: 10.11648/j.ss.20170605.11

Received: March 26, 2017; Accepted: April 17, 2017; Published: September 8, 2017

\begin{abstract}
The governments at all levels in China occupy a dominant position in the higher education investment; they should fully guarantee the investment in higher education. Through the analysis of the sources of the funding of Chinese colleges and universities in 1992-2013, this paper examines the adequacy of the state investment in China's higher education during the transition period. It also discusses the factors that lead to higher education in china, including the national basic construction investment insufficient structural fiscal investment problems caused by financial appropriation balances the illusion, Chinese government departments for policy coordination of the work of colleges and universities lack the corresponding requirements, and the investment is not sufficient. Thus, the paper puts forward some corresponding strategies and suggestions on how to realize the input adequacy and support the development scientifically and efficiently.
\end{abstract}

Keywords: Transitional Period, Higher Education Investment, State Investment, Adequacy

\section{The significance of State Investment in Higher Education During of the Transitional Period}

In 1992, China began to establish a socialist market economic system, fully into the social transformation period. With the rapid growth of economy and the development of higher education, the source of higher education is no longer a single government support in the past. It gradually shows a diversified development trend. The higher education investment structure can not only meet the needs of the development of higher education, also can meet the social demand for higher education investment, and the investment efficiency is higher. The society demand for higher education investment refers to the investment number and proportion in the field of different investment subjects, it can promote the development of higher education investment needs are met. With higher investment efficiency that is the proportion of government, society and individuals to invest in this area can make investment more efficient use or not. Therefore, the above several parts of the composition and proportion of funds is the key to explore whether the investment structure of higher education is scientific and reasonable.

For higher education funds, the government's investment has occupied an absolute dominant position in its source. There are two reasons: first, because of the nature of quasi public goods, the government's financial input is the key to ensure its development. Second, the externality has indicated that the whole society can benefit from the investment, the development can cultivate a large number of high-quality talents for the rapid growth of economy, and also can promote the national comprehensive quality has been greatly improved, promoting the construction and development of material and spiritual civilization. [1] Therefore, to ensure that the administrative organs of investment in this area, can promote the development of China's higher education. In addition, China's law gives full protection for the main position of the government's financial investment in the higher education investment structure. The higher education law of China clearly states: "China will establish a higher education 
funding mechanism that financial allocation as the leading factor and other ways and means to raise funds as auxiliary." The amount and proportion of government investment is one of the most direct factors affecting the rapid development of China's higher education.

Among them, the state's financial higher education funds: including the corresponding career funding and infrastructure funding which belong to the scope of China's budget for higher education funding, taxes and fees for higher education collected by administrative organ Etc.. Although China has achieved rapid economic development during the period of economic and social transformation since 1992, revenue has increased year by year, and the annual growth rate has continued to increase. However, the proportion of national financial education funds in GDP and the proportion of financial expenditure in financial expenditure did not show a steady upward trend. [2] Therefore, the country still needs to increase investment in education.

\section{Analysis of the Status Quo of China's Higher Education Investment in the Transitional Period}

Table 1. Input of higher education of China during 1992-2013 Unit: 100 million Yuan.

\begin{tabular}{|c|c|c|c|c|c|c|c|c|c|c|c|c|}
\hline \multirow[b]{2}{*}{ Year } & \multirow[b]{2}{*}{ Total } & \multicolumn{5}{|c|}{ Financial education funds } & \multicolumn{3}{|c|}{ Social input } & \multicolumn{2}{|c|}{ Business income } & \multirow{2}{*}{$\begin{array}{l}\text { Other } \\
\text { education } \\
\text { funds }\end{array}$} \\
\hline & & Total & $\begin{array}{l}\text { Budgetary } \\
\text { expenditure }\end{array}$ & $\begin{array}{l}\text { Educational } \\
\operatorname{tax}\end{array}$ & $\begin{array}{l}\text { School } \\
\text { revenue }\end{array}$ & $\begin{array}{l}\text { Other financial } \\
\text { expenditure }\end{array}$ & Total & $\begin{array}{l}\text { Social } \\
\text { donation }\end{array}$ & $\begin{array}{l}\text { Host } \\
\text { input }\end{array}$ & Total & $\begin{array}{l}\text { Tuition } \\
\text { fees }\end{array}$ & \\
\hline 1992 & 162.08 & 146.76 & 121.76 & - & 25.01 & & - & - & & 9.11 & 4.58 & 6.21 \\
\hline 1993 & 167.22 & 153.45 & 138.83 & 0.20 & 14.42 & 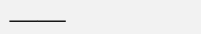 & 1.25 & 1.25 & - & 10.36 & 10.36 & 2.16 \\
\hline 1994 & 220.48 & 181.00 & 160.70 & 0.64 & 19.67 & & 2.87 & 2.87 & & 26.23 & 26.23 & 10.38 \\
\hline 1995 & 292.20 & 229.72 & 198.15 & 1.92 & 26.61 & 3.03 & 4.42 & 4.42 & & 44.52 & 44.52 & 13.54 \\
\hline 1996 & 345.55 & 264.56 & 227.98 & 3.60 & 28.81 & 4.16 & 5.42 & 5.42 & & 56.37 & 56.37 & 19.21 \\
\hline 1998 & 587.04 & 375.08 & 340.53 & 8.11 & 11.80 & 14.64 & 11.82 & 11.82 & & 162.6 & 85.47 & 37.54 \\
\hline 1999 & 753.31 & 465.40 & 420.10 & 7.73 & 13.17 & 24.40 & 16.40 & 16.40 & & 233.63 & 137.88 & 37.88 \\
\hline 2000 & 966.62 & 556.28 & 496.05 & 9.17 & 17.37 & 33.70 & 15.34 & 15.34 & & 345.04 & 216.69 & 49.95 \\
\hline 2001 & 1213.47 & 657.31 & 590.07 & 7.80 & 17.21 & 42.22 & 17.43 & 17.43 & & 472.65 & 312.43 & 66.08 \\
\hline 2002 & 1527.50 & 781.71 & 705.91 & 9.25 & 17.58 & 48.97 & 27.95 & 27.95 & & 643.66 & 426.45 & 74.178 \\
\hline 2003 & 1778.60 & 869.49 & 780.32 & 11.06 & 19.53 & 58.58 & 25.74 & 25.74 & & 779.09 & 548.75 & 104.28 \\
\hline 2004 & 2103.50 & 1001.44 & 898.24 & 12.97 & 22.64 & 67.59 & 21.63 & 21.63 & & 949.5 & 693.87 & 130.93 \\
\hline 2006 & 3057.77 & 1302.52 & 1246.85 & - & - & - & 253.81 & 19.48 & 234.3 & 1291.04 & 906.07 & 210.4 \\
\hline 2007 & 3762.30 & 1648.12 & 1434.14 & 19.12 & 19.21 & 175.65 & 59.39 & 27.47 & 31.92 & 1766.16 & 1277.45 & 288.64 \\
\hline 2008 & 4346.88 & 2062.46 & 1809.23 & 34.35 & 13.20 & 205.67 & 59.17 & 29.00 & 30.17 & 1932.88 & 1474.29 & 292.38 \\
\hline 2009 & 4782.78 & 2327.38 & 2020.38 & 46.61 & 16.50 & 243.89 & 59.49 & 26.39 & 33.10 & 2083.66 & 1593.91 & 312.25 \\
\hline 2010 & 5629.08 & 2965.32 & 2495.57 & 70.69 & 12.30 & 386.77 & 56.95 & 29.98 & 26.96 & 2276.77 & 1724.54 & 330.04 \\
\hline 2011 & 7020.87 & 4096.33 & 3552.90 & 100.74 & 18.71 & 423.98 & 76.74 & 43.45 & 33.29 & 2462.00 & 1862.36 & 385.80 \\
\hline 2013 & 8178.61 & 4933.39 & 4502.73 & 159.33 & 18.40 & 252.92 & 77.62 & 43.59 & 34.03 & 2746.32 & 2048.39 & 421.28 \\
\hline
\end{tabular}

Data source: China National Bureau of Statistics website of China education budget Yearbook (1992-2013).

The rapid development of higher education in China's transition period is due to the continuous rise of investment. In Table 1, through analyzing the Chinese college funding structure in 1992-2013, we can divide the ordinary university funding sources into the following: "Budgetary education funds", "social donation funds", "Tuition" and "other education funds" etc. Among them, the financial education funds are always the most important source channel. In order to properly handle the problem of insufficient funds, China should increase its investment in education. Individual should reasonably share the education costs. Government should fully support the development of social donation to university. [3]

Table 2. The scale and proportion of China's higher education investment in 1992-2013 (Scale: 100 million Yuan; accounting for: \%).

\begin{tabular}{|c|c|c|c|c|c|c|c|c|}
\hline \multirow{2}{*}{ Year } & \multicolumn{2}{|c|}{ State input } & \multicolumn{2}{|c|}{ Social input } & \multicolumn{2}{|c|}{ Personal input } & \multicolumn{2}{|l|}{ Total } \\
\hline & Scale & Proportion & Scale & Proportion & Scale & Proportion & Scale & Proportion \\
\hline 1992 & 146.76 & 90.55 & - & 0 & 4.58 & 2.83 & 162.08 & 100 \\
\hline 1993 & 153.45 & 91.83 & 1.25 & 0.74 & 10.36 & 6.2 & 167.22 & 100 \\
\hline 1994 & 181 & 82.17 & 2.87 & 1.29 & 26.23 & 11.9 & 220.48 & 100 \\
\hline 1995 & 229.72 & 78.62 & 4.42 & 1.51 & 44.52 & 15.24 & 292.2 & 100 \\
\hline 1996 & 264.56 & 76.56 & 5.42 & 1.57 & 56.37 & 16.31 & 345.55 & 100 \\
\hline 1997 & 308.86 & 74.41 & 8.96 & 2.16 & 72.39 & 17.44 & 415.1 & 100 \\
\hline 1999 & 465.4 & 61.78 & 16.4 & 2.18 & 137.88 & 18.3 & 753.31 & 100 \\
\hline 2000 & 556.28 & 57.55 & 15.34 & 1.59 & 216.69 & 22.42 & 966.62 & 100 \\
\hline 2001 & 657.31 & 54.17 & 17.43 & 1.44 & 312.43 & 25.75 & 1213.47 & 100 \\
\hline 2002 & 781.71 & 51.18 & 27.95 & 1.83 & 426.45 & 27.92 & 1527.5 & 100 \\
\hline 2003 & 869.49 & 48.89 & 25.74 & 1.45 & 548.75 & 30.85 & 1778.6 & 100 \\
\hline 2004 & 1001.44 & 47.61 & 21.63 & 1.03 & 693.87 & 32.99 & 2103.5 & 100 \\
\hline
\end{tabular}




\begin{tabular}{|c|c|c|c|c|c|c|c|c|}
\hline \multirow{2}{*}{ Year } & \multicolumn{2}{|c|}{ State input } & \multicolumn{2}{|c|}{ Social input } & \multicolumn{2}{|c|}{ Personal input } & \multicolumn{2}{|l|}{ Total } \\
\hline & Scale & Proportion & Scale & Proportion & Scale & Proportion & Scale & Proportion \\
\hline 2005 & 1128.54 & 42.46 & 202.69 & 7.63 & 837.91 & 31.53 & 2657.86 & 100 \\
\hline 2006 & 1302.52 & 42.6 & 253.81 & 8.3 & 906.07 & 29.63 & 3057.77 & 100 \\
\hline 2007 & 1648.12 & 43.81 & 59.39 & 1.58 & 1277.45 & 33.95 & 3762.3 & 100 \\
\hline 2008 & 2062.46 & 47.45 & 59.17 & 1.36 & 1474.29 & 33.92 & 4346.88 & 100 \\
\hline 2009 & 2327.38 & 48.66 & 59.49 & 1.24 & 1593.91 & 33.33 & 4782.78 & 100 \\
\hline 2010 & 2965.32 & 52.68 & 56.95 & 1.01 & 1724.54 & 30.64 & 5629.08 & 100 \\
\hline 2011 & 4096.33 & 58.34 & 76.74 & 1.09 & 1862.36 & 26.53 & 7020.87 & 100 \\
\hline 2013 & 4933.39 & 60.32 & 77.62 & 0.95 & 2048.39 & 25.05 & 8178.61 & 100 \\
\hline
\end{tabular}

Data source: China National Bureau of Statistics website of China education budget Yearbook (1992-2013)

As can be seen from table 2, there is a considerable gap between each of these funds. At present, public universities still occupy a dominant position in China's higher education. In 1992, the state financial higher education funds were 14.67 billion Yuan, tuition and fees were 458 million. By 2013, we can clearly see that financial higher education funds reached 49.33 billion Yuan, social capital investment and donation funds were 7.76 billion Yuan, tuition is 204.84 billion Yuan, they has a large rise.

As we can see from Figure 1, the growth of Financial Higher Education and tuition and fees is very rapid.

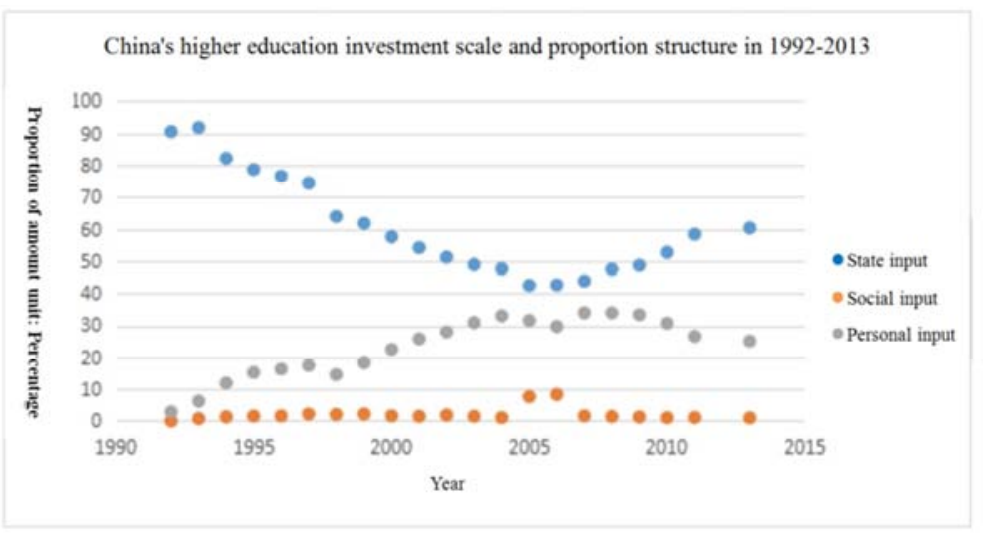

Figure 1. Histogram of China's higher education investment scale and proportion structure in 1992-2013.

Taking 2005 as the dividing line, the evolution process of China's higher education investment structure can be divided into two stages: in the early stage, the proportion of national investment continued to decline, the proportion of personal investment continued to rise; In the later stage, the proportion of the country's investment rebounded, while the proportion of personal investment decreased gradually. The early 90 s of last century, the proportion of state invested in the total investment in was not less than $90 \%$. In 1994, after the universities began to collect tuition fees, although the absolute number of national investment continued to rise, but the proportion of its gradual decline, to 2005 to the lowest point $(42 \%)$, Since then, the proportion of its investment rebounded to some extent. By 2014, the proportion reached $60 \%$, as the same level as in 2000 . Overall, in the transition stage, the proportion of state investment present an "high-low-high" U shaped fluctuations. [4]

China's higher education investment scale and proportion structure in 1992-2013

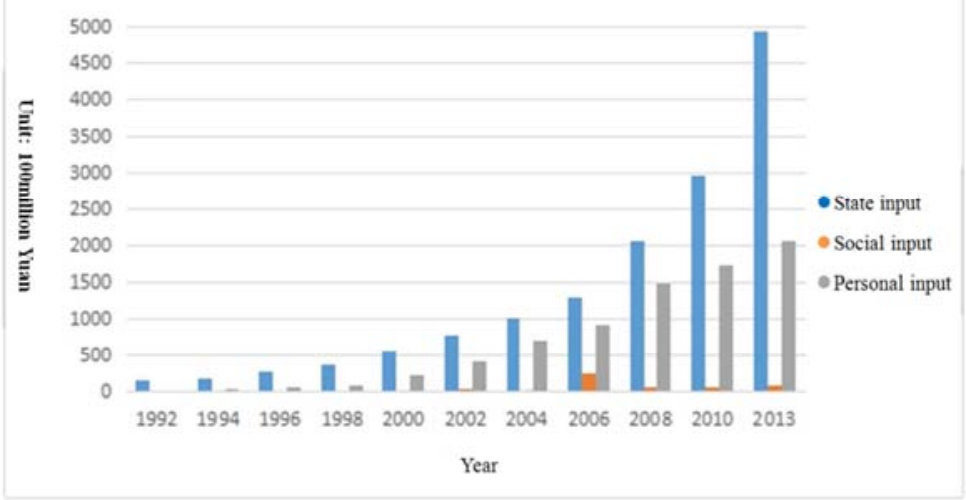

Figure 2. China's higher education investment scale and proportion structure in 1992-2013. 
Although the number of funds in these parts is a large proportion of the rise, however, the proportion of the various parts has undergone significant changes. As we can see from Figure 2, the national financial funds in the proportion of the total funds showed a trend of continuous decline. In 1992, the proportion up to $90.55 \%$, while in 2013 its proportion has dropped to $60.32 \%$. In 2005 and 2006, its proportion even dropped to $42 \%$. Although there has been a certain degree of recovery, but the overall trend is continued to decline. This shows that in the structure of higher education funding, despite the rapid rise of fiscal expenditure, but compared to the total investment scale growth, it has been a significant lag. Moreover, the scale of social donation funds continued to rise, but the proportion of the total funds is not high, and showed a trend of sustained decline. The proportion of tuition expenses in the total funds showed a steady upward trend. In 1992, the proportion was only $2.83 \%$, but in 2013 the proportion has increased to $25.05 \%$. The proportion of national investment showed a gradual downward trend, the proportion of tuition continued to increase. Therefore, we can see the financial support for higher education continued to decline. The reduction is actually transferred to the area of personal tuition. This change has a certain degree of social risk, should be given full attention.

\section{Analysis of the Factors Affecting the State Investment of China's Higher Education in the Transitional Period}

\subsection{National Infrastructure Investment Is Insufficient; College Debt Is Serious}

In the case of the expansion of the scale of higher education, it is necessary to expand the campus and optimize the teaching conditions. Compared to 1998, the area of China's colleges and universities reached 2 million and 120 thousand acres in 2007, with a significant rise. The school building area of 580 million square meters, turned over several times. Fixed assets reached 814.7 billion Yuan, an increase of 720 billion, equivalent to the previous 8.61 times. Nevertheless, this expansion rate is still unable to keep up with the growth rate of the annual enrollment of colleges and universities. Public colleges and universities in China have a major position, and the administrative organs at all levels are the main founders of all kinds of colleges and universities. However, the relevant data show that in the same period, including treasury bonds, the national budget for investment in the construction of the university is only 84 billion Yuan, which was not even $10 \%$ of the total demand. It is because of the states investment in infrastructure is not valued, as well as the special financial management environment, the colleges and universities raise their own funds to invest in campus infrastructure and optimize the teaching conditions. It led the bank debt of current Chinese University reached an alarming about 260 billion Yuan. The shortage of national capital investment is one of the important factors causing the serious colleges and universities indebted.

\subsection{The Structural Problems of Financial Input, the False Statement of Appropriation}

"Quota plus special" is the mainly mode of administrative organs for the funding of higher education. For a long time, the reason for the lack of financial investment in higher education is that the quota allocation is relatively low in the personnel training cost of colleges and universities. There are considerable differences between the average quota allocation and cost. Relevant data shows, in 2005-2007, the cost standard of per student of the colleges and universities directly under the jurisdiction of the Ministry of Education is 26.7 thousand Yuan, but the real data is only 19.1 thousand Yuan. However, the original engineering student funding quota is 6878 Yuan, since 2008 to increase the amount, it is close to 8000 Yuan, but just only $42 \%$ of the actual cost. [5] On the other hand, there is a certain proportion of the financial change into special input, which led to the structural problems of the inputs becoming more prominent. Take this kind of school, the last three years, the increase in the amount of funding are basically special, they accounted for $34 \%$ in the allocation of funds. The special funds of some colleges are even accounted for higher than $50 \%$ in the total allocation proportion. The structural problem is obvious: the proportion of the quota and the special appropriation is not balanced. This will result in the fact that the allocation funds can not ensure the orderly operation of the school, while the special funds often had a certain amount of surplus. Some colleges and universities have a large number of special funds surpluses, but the bank loans rose sharply. Therefore, the structural problems of government investment should be paid close attention to by the relevant departments and the society.

\subsection{The Lack of Policy Coordination in Colleges and Universities, the Gap of Security Funds}

Because of the limitations of the current management mechanism, the cost of scientific research and social service personnel are basically covered in the scope of education expenditure, in other words, they included in the cost of personnel training. According to the current financial mechanism in China, the salaries and social security expenditure of faculty of colleges and universities are covered in the scope of education funds. Relevant scholars analyzed the financial crisis and governance of OECD national universities. It's clear that higher education scale expands rapidly, the increased of social responsibility of universities; the decreased of the support for universities from administrative organs are important factors to promote the financial crisis. [6] China's current financial management rules and regulations to make this problem more serious. In addition, the administrative organs at all levels are lack of 
effective communication and coordination for the management of colleges and universities. The rules and the relevant requirements do not fully take into account the funding factors and the ability of the colleges and universities. There is a big gap of the security funds.

\section{Realizing the Development of Higher Education by the Input Adequacy}

With the deepening of the transition period, the quality of life of the public has been significantly improved, China's higher education is also showing a rapid development trend. The scale of China's higher education continues to expand, the quality has been significantly improved, the enrollment rate continues to rise, and the structure has been significantly improved. However, inadequate funding is still one of the key problems restricting the development of China's higher education. Therefore, how to make a scientific and reasonable higher education fiscal policy to ensure that it can get sufficient financial support is the key to the development of China's higher education.

\subsection{Promoting Economic Growth, Ensure the Proportion of National Investment}

The rapid development of the economy has increased the Chinese government's ability to invest in higher education. Economic development provides a guarantee for the government to increase the investment in higher education. Adequate input for higher education is the material basis for ensuring long-term and healthy development of higher education. It is a very important function of government public finance. Steady economic development is the key to the sustained growth of national financial resources and national education investment. Therefore, the administrative organs should put public education responsibility and public finance function in place, by maintaining the stable development of the economy, increase investment in education, so as to promote the improvement of expenditure structure. In addition, the government should focus more on the quality of higher education, to promote the development of the connotation, and to improve the efficiency of the use of national investment.

\subsection{Government to Help Repay the Loan, Improve Financial Efficiency}

In recent years, with the rapid development of China's higher education, in order to expand the scale of enrollment, the colleges and universities has been always building new campus and creating new professional. However, the funds of the government provides for colleges and universities ware limited, which can only solve the problem of insufficient funds through bank loans. Some colleges and universities loans far beyond the level of their ability to repay loans, and even more, some colleges and universities cannot even pay the interest. Lack of funds has had a negative impact on the quality of higher education. Some colleges and universities in order to repay the loan, forced to reduce student funding and office funds, the quality of education cannot be fully protected. [7] Colleges and universities due to the expansion of enrollment generate related loans; the state should give specific and practical solutions. Because of the huge debt of colleges and universities is due to the expansion of enrollment, inadequate infrastructure and the lack of government investment. Therefore, it should be based on the actual size and status of enrollment to determine. Administrative organs should abandon the thinking that "Dare loan school put more" and "More loans are rational, small loans are silly". Strengthen management, improve efficiency.

\subsection{Reduce the "Three Public Funds" to Develop Higher Education}

In China's fiscal expenditure, the "Three Public Funds" of the public officials occupy a large proportion. "Three Public Funds" contributed to the wind of corruption, extravagance and waste, seriously hindered the development of China's political and economic. Moreover, the high level of "Three Public Funds" led to the lack of financial resources in the field of people's livelihood, the field of education is also affected by it. Therefore, in order to better develop China's higher education, the Chinese government should strengthen and improve financial macro-control, further adjust the structure, strengthen the financial expenditure management, compression "Three Public Funds", allowing it to tilt to the people's livelihood, promote financial funds can achieve efficient use of funds and ensure the rational use and safety, to ensure access to higher education finance sufficient support.

\subsection{Measure Education Investment, Macro and Micro Indicators Implement Simultaneously}

The input of higher education is not only closely linked with the input of total funds, but also closely related to the scale of running schools. Therefore, in the medium and long term planning should not only determine the proportion of education investment in the GDP, but also to determine the proportion of public institutions of higher education funding in the cost of personnel training. As colleges and universities, the proportion of student funding quota in the average cost is actually more valuable, and can reflect more information. The key is to increase the proportion of fixed investment in total investment. [8] It is of great value and significance for every institution of higher learning to benefit from the financial support for its future survival and development.

\section{Concluding Remarks}

Adequate funding and sound investment system is an important prerequisite for the development of China's higher education. It is also the key guarantee to create "double first-class ". In recent years, China's investment in higher education has been significantly improved, the government's 
investment in higher education has risen sharply and the social donation is also rising, tuition becomes an important part of higher education funds. They formatted a new situation for the development of diversified sources of funding. It promoted the steady development of China's higher education. However, when fully recognized in the achievements, we should also be aware that there are still a lot of conflicts of China higher education, the funding is not sufficient, the contradiction between supply and demand of investment still not resolved.

\section{Acknowledgements}

This thesis is supported by Social sciences planning project of Jiangxi province (No. 15GL17), postgraduate education and teaching reform foundation of Jiangxi Province of China (No.JXYJG-2013-053), Humanities and Social Sciences foundation of Universities in Jiangxi Province (No.JC1512), Key research foundation of Finance and Economics University of Jiangxi in 2013( No.JXCJ201311)

\section{References}

[1] Cai Keyong, Fan Wenyao, Ma Luting. 2006. Research on the investment system of higher education during the transitional period. Bei Jing: Higher Education Press.

[2] Lu Ke. 2008. Research on the adequacy of local education investment in China during the period of "Fifteen". Proceedings of the 2008 annual meeting of China's Educational Economics. Shanghai: China Society of Education: 723-724.

[3] Ji Junjie. 2016. Analysis of the evolution and rationality of individual investment in the higher education during the transitional period. Higher education research (4): 42-48.

[4] Zhang Jing. 2009. An analysis of the present situation of higher education funding of China. Journal of Nanjing University of Posts and Telecommunications (Social Science Edition) (3): 66-69.

[5] Li Lihui. 2011. Ministry of Finance: public expenditure 2/3 for livelihood. People Daily: 09-30(4).

[6] Xu Mingzhi. 2009. Reflections and suggestions on China's higher education investment. Education Development Research (4): 40-42.

[7] Zhang Yin. 2013. Analysis on the change of investment structure of higher education in China and its influencing factors. Ji'nan: Shandong University: 66-67.

[8] Zhang Jingui, Sun Jie. 2014. Analysis of foreign performance allocation model. Contemporary economy (7): 116-117.

[9] Chang Zhengxia. Female graduate mployment present situation and countermeasure research in western region. $[\mathrm{J}]$, Lan Zhou acdemic journal, 2011(08): 180-184

[10] The Ministry of Education. The State Statistics Bureau. China educational statistic yearbook in 2012 [R], People's Education Press, 2013: 2013. 